\title{
A new category of "future planning" in the activity card sort: Continuity versus novelty in old age
}

\author{
Tsameret Ricon*, Pola Weissman, Naor Demeter \\ Department of Occupational Therapy, Faculty of Social Welfare and Health Sciences, University of Haifa, Haifa, Israel; \\ *Corresponding Author: tricon@univ.haifa.ac.il
}

Received 30 November 2012; revised 29 December 2012; accepted 6 January 2013

\begin{abstract}
The Activity Card Sort (ACS) is a widely used measure for assessing participation in instrumental, leisure, and social-cultural activities. The ACS addresses previous and current activities but not future activity plans. The purpose of the study was to extend the ACS to include future planning. Previous research indicates that participation in activities and future planning is positively related to life satisfaction, and increased well-being and that these positive effects were most pronounced for adults 60 years and older. The current study participants were 60 Israeli adults aged 55 - 74 years. The research finds future planning to be widespread, common and significant among older adults. Moreover, it was found that older people planned to continue previous activities more that they planned new activities for the future, indicating more continuity than innovation among the participants in this study. Participants with higher current or past activity levels planed a greater number of future activities. Construct validity using known group method showed the extended ACS to have discriminant validity with respect to age (younger participants were more active) and gender (highly physical activities were favored by men). MANOVA repeated measures and Pearson correlations demonstrated moderate-high test-retest reliability for the extended ACS.
\end{abstract}

Keywords: Activity Card Sort; Continuity; Innovation; Older Adults; Reliability \& Validity

\section{INTRODUCTION}

As life expectancy increases, so does the size of the elderly population. Older people have more free time and are more active in comparison with their predecessors [1,
2]. Research has indicated that greater overall activity level in older adults was related to greater happiness, better function, and reduced mortality [3]. Moreover, evidence has shown that activities associated with leisure and independent living, is a meaningful part of their lives and participation in occupational areas of performance. Independent living activities, referred to as instrumental activities of daily living (IADL), include activities such as preparing meals or shopping, $[4,5]$. Leisure activities include social and productive activities, as well as more solitary activities (e.g., reading, handwork, hobbies) and were related to feelings of well-being, function and happiness and to a sense of engagement with life [3]. Consequently, these activities are a primary focus of occupational therapy (OT) interventions for this population.

The World Health Organization's International Classification of Functioning, Disability and Health emphasizes the significance of promoting health and well-being by enabling participation, and defines participation as a person's involvement in life situations [6]. However, the greatest influence on activity patterns is the age of the participant, with the diversity and frequency of leisure activities decreasing as participant age increases [7]. This tendency may be associated with age-related changes to people's lifestyle and family structures [4,5].

The concept of "future planning" has been well studied in the gerontology literature of the last two decades and shows that most future planning occurs around retirement age [8-11]. Retirement involves marked changes within a short period of time and is therefore a significant transition in life requiring a process of planning [8].

In planning for the post-retirement phase of their lives, older adults have been found to adopt two main strategies: continuity and innovation. Continuity has been defined as the maintenance of familiar leisure activities into retirement and is a major characteristic of the post-retirement period $[12,13]$. Therefore leisure activities are likely to be continued throughout the ageing process, despite physical changes resulting from the normal ageing process, in order to preserve and maintain existing individual and social identities [14-18]. Continuity ap- 
pears to aid adjustment to old age and is seen as a strategy that promotes coping. Older people seek to develop activity patterns that are as stable as possible in order to maintain the social and psychological characteristics they obtained through life. Continuity serves as an attribute of successful adaptation to old age and its associated difficulties, such as deteriorating health status, decreased financial income and narrowing social circles [9,14-19].

The phenomenon of innovation is relatively unexplored in the literature. Evidences show that innovation in old age is less common [20-22], although some evidence exists showing that older adults do tend to innovate in their leisure participation [23]. While preserving and maintaining existing individual and social identity is important to well-being during the ageing process, aging may also provide opportunities for engaging in new experiences [10,24-26].

In the context of leisure, innovation is defined as an older adult's post-retirement participation in at least one leisure activity in which he or she did not engage prior to retirement. Innovation in leisure activities may contribute to a feeling of well-being in old age and is not only about the unknown new activity, since it also reflects a new source for a familiar experience [10]. Innovation is more commonly adopted by women than men [27], and characterizes people who retired from a full time job, who perceive their health as good, retired out of free will, have a Western cultural background, and expect a longerterm retirement [23]. However, few researchers have focused on innovation and thus far only in a Western context, such that it is not clear if innovation is also common elsewhere.

Investigating future planning by older adults in an OT context requires the use of suitable tools through which to gather relevant information and create an occupational profile. This process enables the therapist to establish intervention goals and outcome measures together with the client [28]. Many evaluation tools assess occupational performance [29,30], however very few assess leisure and IADL activities in an ecological context [31]. Although a few assessment tools assess the leisure and IADL occupational domains, most are structured as questionnaires or scales (e.g., COTE [32], COPM [33]). The uniqueness of the ACS lies in the life-like pictures it presents to the person to sort. Examples of occupational therapy evaluation tools for leisure are the Interest Checklist [34] and the Occupational Questionnaire [35], while the Lawton and Brody questionnaire offers a means of assessing the IADL abilities of older adults. Although these questionnaires are reliable and valid [34$36]$, they require the ability to understand written text in addition to possessing an intact verbal memory. They are therefore unsuitable for sections of the older adult population in whom such skills may have deteriorated.
The Activity Card Sort (ACS) [37,38] evaluates past and current participation in instrumental, leisure and social activities. It was designed originally for people with Alzheimer's disease [39] and is used today to evaluate how older adults cope with various diseases or life events. The ACS has been studied in numerous countries and was found reliable and valid [40-43]. The ACS involves sorting pictures of leisure, social-cultural, and IADL activities into categories. The visual representation method is less threatening than completing a form and achieves better client cooperation [44]. Although it provides valuable information on past and present activities, the ACS does not provide information regarding the activities in which a person plans to participate in future. A future planned activity suggests that the client plans to adopt continuity and/or innovation strategies. The knowledge is required in order to create a full client activity profile in an OT intervention and to identify meaningful future occupations.

Thus, there is insufficient information in the literature regarding future planning by older adults. This study seeks to address this gap by investigating a tool for the collection of future planning data from older adults in an occupational therapy setting. The aim of the current study is to expand the ACS tool by adding a new "Future Activity" sorting category to the existing "Past Activity" and "Current Activity" sorting categories in order to shed light on continuity versus novelty in activities of older age. Three main research questions were defined: 1) Do older people plan social and recreational everyday activities for the future? 2) Are older people more likely to plan future activities in which they have been engaged in the past, or new ones? 3) What is the validity and reliability of the extended ACS after adding a new category?

The purpose of this new category is to identify activities in which the person plans to participate in the near future and to differentiate between innovation and continuity in the choice of future activities. The uniqueness of the current study lies in its focus on planned future leisure activities among older adults with the objective of promoting life quality and well-being. The study was undertaken with the approval of the author of the ACS, Prof. Carolyn M. Baum.

\section{METHOD}

The study utilized a convenience sample of 60 participants, aged 55 - 75 years. The participants live near Haifa and were recruited from the authors' acquaintances. The sample was divided into two age groups used in the literature [45]: older adults (aged 55 - 64 years) and elderly adults (aged 65 - 74 years). All the participants met the inclusion criteria (see below), had not been diagnosed with a mental/physical disability or neurological disease 
and possessed normal cognitive abilities. The demographic characteristics of the sample are presented in Table 1.

Each age group included a similar number of men and women. Mean educational attainment level was 14.53 years $(\mathrm{SD}=3.29)$. All the participants were Hebrew speakers and were independent with respect to activities of daily living (ADL) and IADL. All participants signed an informed consent form.

\subsection{Instruments and Inclusion Criteria}

\subsubsection{The Screening Questionnaire}

The questionnaire was developed for this research and consisted of eight questions that asked whether the participant was currently diagnosed with a mental/physical disability or neurological disease. Only participants who answered "no" to all eight questions were included in the study.

\subsubsection{Mini-Mental State Examination (MMSE)}

The MMSE [45] is a common neuropsychological screening test in field research and clinical practice that evaluates the general cognitive ability of adults. The maximal score is 30 . A score of 24 - 30 indicates normal cognitive ability and achievement of this score was the second requirement for inclusion in this study.

\subsubsection{Demographic Questionnaire}

This questionnaire was used to collect demographic information concerning the participants with respect to gender, income level, residence, highest educational attainment, and place of birth.

\subsubsection{Activity Card Sort}

The ACS includes 88 activity cards representing realistic pictures of older adults engaged in four activity domains: IADL, social-cultural leisure, low physical leisure, and high physical leisure. Three versions of the ACS are available: one for hospitalized older adults, a second for those in a recovery period, and a third for older adults living independently in the community. The current study employed a Hebrew translation of the third version of the ACS $[41,46]$.

Baum (1995) reported on the construct and content validity of her original ACS measure among 72 Alzheimer patients in different stages of the disease [37]. Gonen et al. [46] found the measure to have construct and content validity among healthy older adults in Israel, and a high significant internal consistency in the IADL domain $(r=0.83)$ and in the social-cultural domain $(r=$ $0.80)$. It has moderate significant reliability in the low physical leisure $(\mathrm{r}=0.66)$ and high physical leisure $(\mathrm{r}=$ 0.61 ) domains.

Table 1. Demographic characteristics of the sample as numbers and percentages.

\begin{tabular}{|c|c|c|c|c|c|c|}
\hline Variable & & $\begin{array}{c}\text { Older } \\
(55-64 \text { years }) \\
(n=33)(55 \%)\end{array}$ & $\begin{array}{c}\text { Elderly } \\
(65-74 \text { years }) \\
(n=27)(45 \%)\end{array}$ & $\begin{array}{c}\text { Male } \\
(\mathrm{n}=28) \\
(46.7 \%)\end{array}$ & $\begin{array}{l}\text { Female } \\
(\mathrm{n}=32) \\
(53.3 \%)\end{array}$ & $\begin{array}{c}\text { Total } \\
(\mathrm{n}=60) \\
(100 \%)\end{array}$ \\
\hline \multirow[t]{3}{*}{ Income Level } & Low & 0 & $4(14.8 \%)$ & $2(7.1 \%)$ & $2(6.2 \%)$ & $4(6.7 \%)$ \\
\hline & Medium & $30(90.9 \%)$ & $16(59.3 \%)$ & $19(67.9 \%)$ & $27(84.4 \%)$ & $46(76.7 \%)$ \\
\hline & High & $3(9.1 \%)$ & $7(25.9 \%)$ & $7(25 \%)$ & $3(9.4 \%)$ & $10(16.7 \%)$ \\
\hline \multirow{3}{*}{ Residence } & Kibbutz & $5(15.2 \%)$ & $3(11.1 \%)$ & $4(14.3 \%)$ & $4(12.5 \%)$ & $8(13.3 \%)$ \\
\hline & Village & 0 & $3(11.1 \%)$ & $2(7.1 \%)$ & $1(3.1 \%)$ & $3(5 \%)$ \\
\hline & Other & $5(15.2 \%)$ & $1(3.7 \%)$ & $3(10.7 \%)$ & $3(9.4 \%)$ & $6(10 \%)$ \\
\hline Highest & Elementary & $1(3 \%)$ & $4(14.8 \%)$ & $3(10.7 \%)$ & $2(6.2 \%)$ & $5(8.3 \%)$ \\
\hline \multirow[t]{5}{*}{ Attainment } & Vocational & $11(33.3 \%)$ & $8(29.6 \%)$ & $12(42.9 \%)$ & $7(21.9 \%)$ & $19(31.7 \%)$ \\
\hline & Academic & $18(54.5 \%)$ & $11(40.7 \%)$ & $9(32.1 \%)$ & $20(62.5 \%)$ & $29(48.3 \%)$ \\
\hline & Israel & $20(60.6 \%)$ & $13(48.1 \%)$ & $17(60.7 \%)$ & $16(50 \%)$ & $33(55 \%)$ \\
\hline & Europe & $3(9.1 \%)$ & $2(7.4 \%)$ & $2(7.1 \%)$ & $3(9.4 \%)$ & $5(8.3 \%)$ \\
\hline & USA & $1(3 \%)$ & $1(3.7 \%)$ & $1(3.6 \%)$ & $1(3.1 \%)$ & $2(3.3 \%)$ \\
\hline \multirow[t]{4}{*}{ Place of Birth } & Asia & $1(3 \%)$ & $5(18.5 \%)$ & $3(10.7 \%)$ & $3(9.4 \%)$ & $6(10 \%)$ \\
\hline & Africa & $3(9.1 \%)$ & $1(3.7 \%)$ & $1(3.6 \%)$ & $3(9.4 \%)$ & $4(6.7 \%)$ \\
\hline & Soviet Union & $5(15.2 \%)$ & $4(14.8 \%)$ & $4(14.3 \%)$ & $5(15.6 \%)$ & $9(15 \%)$ \\
\hline & Other & 0 & $1(3.7 \%)$ & 0 & $1(3.1 \%)$ & $1(1.7 \%)$ \\
\hline
\end{tabular}


The tool was found to distinguish between different age groups $(\mathrm{t}=5.46, p<0.0001)$ [43] thus establishing the construct validity of the Hebrew ACS and its appropriateness for a population of older Israelis with and without disabilities. In another study conducted in Israel, the known-groups method was used to support construct validity between groups with and without a disability [41]. This study also revealed a significant correlation between the test and retest results $(r=0.897)$.

\subsection{Study Procedure}

The ethics committee of the University of Haifa granted approval for this study. To increase inter-rater reliability, the OT student examiners who administered the study instruments (i.e., the first two authors) experienced the assessment and scoring process themselves before conducting assessments in the community Data collection in the community took place in the summer over a period of 4 months.

Participants were first approached through a preliminary telephone inquiry during which the examiners administered the screening questionnaire orally. Subsequent data collection was conducted by the same examiner in the participant's home in comfortable conditions (lit room with a comfortable chair and table). The purpose of the project was explained to participants, who were informed that their data will remain anonymous, after which all of the participant gave signed consent to participate in the study. Following this, all participants completed the demographic questionnaire and MMSE screening test.

The ACS assessment was then administrated in its original version, which asks participants to sort the cards into the categories of: "Never done before", "Haven't done since I was 50/60" (depending on participant's age), "Doing now", "Doing less", and "Gave up". Each activity domain was scored separately and a total score was summed. The sum of the activities the participant was "Doing now" plus those s/he was "Doing less" constituted the current activity (CA) score. The sum of previously performed activities, which included all the activities the participant had classified as "Doing now", "Doing less" and "Gave up", were regarded as activities that had been "Done in the past" and constituted the past activity (PA) score. A retained activity score was calculated by dividing the number of CA by the number of PA, with the result expressed as a percentage.

After the researcher had encoded the data obtained from the original ACS version, the participant was instructed to "please go over the cards again and place each picture of an activity you plan to do in the future under the category of 'I plan to do in the future'. This includes activities that you participate in now and plan on continuing, activities in which you participated in the past and plan to return to, and activities that you never participated in before but plan to start doing". Scoring after the addition of the new category was repeated for the whole assessment and for each activity domain separately, after which new scoring categories were created. The future activity (FA) score was the total sum of future activities in all the test domains. Within this total, the new FA score was the total sum of activities the participant mentioned $\mathrm{s} /$ he had not participated in the past but was planning to do in the future. The continuing FA score was a total sum of activities a participant mentioned $\mathrm{s} /$ he had done in the past and was planning to do in the future. A novelty percentage score was obtained by dividing the new FA score by the continuing FA score.

The test-retest reliability of the expanded ACS was measured on 20 of the original participants by re-administering the new version of ACS a second time, $7-8$ weeks later.

\subsection{Data Analysis}

The data were analyzed using SPSS (Version 16). Descriptive statistics means, and standard deviations (SD) were used to present the percentage of novelty and FA scores. Pearson's correlations examined the correlation between: future planned activities (innovation and continuity) and the past activity (PA vs. FA) levels; and the current and future activity (CA vs. FA) levels. Construct validity using the known-groups method included comparisons between the two age groups (55 - 64, $65-74$ years) and genders through the use of a two-way MANOVA. Test-retest reliability was examined by using MANOVA repeated measures testing and Pearson correlations. $p$-values of 0.05 or less $(p \leq 0.05)$ were considered significant.

The known-groups method is a common method of supporting construct validity. The known-groups methods evaluates the test's ability to discriminate between the groups based on the groups demonstrating different mean scores on the test.

\section{RESULTS}

\subsection{Correlations between Past and Future Activity Levels and between Current and Future Activity Levels}

Pearson's correlations revealed a high significant correlation between PA vs. FA levels $(\mathrm{r}=0.71 ; p<0.001)$ and between CA vs. FA levels $(\mathrm{r}=0.77 ; p<0.001)$. Correlations were found both for the total ACS total score and for each domain score independently (Table 2).

These results indicate that participants who were more active in the past and/or are more active in present plan to continue being active in future. 
Table 2. Pearson correlations between activity card sort (ACS) scores: future activities compared to past and current activities.

\begin{tabular}{lcc}
\hline & \multicolumn{2}{c}{$\begin{array}{c}\text { Correlation (r) with planned } \\
\text { future activity }\end{array}$} \\
\hline ACS domain & Past activities & Current activities \\
\hline Total score (for all domains) & 0.71 & 0.77 \\
IADL domain & 0.51 & 0.59 \\
Social-cultural domain & 0.58 & 0.70 \\
Low physical leisure domain & 0.60 & 0.65 \\
High physical leisure domain & 0.60 & 0.74 \\
\hline
\end{tabular}

Note: all values are significant at the $p<0.001$ level.

\subsection{Percentage of Novelty}

A third of the participants $(n=20 ; 33.3 \%)$ planned on continuing FAs only, that is, only FAs that were familiar from current or past engagement in them. However, most of the participants $(n=40 ; 66.7 \%)$ intended to participate in a mixture comprising $16-48$ continuing FAs $(\bar{x}=49$ activities) and a few $(\leq 5)$ new FAs. Two-way MANOVA revealed no significant differences between the age or gender groups. No age-gender interaction effect was found with respect to the novelty and total scores for any test domain (data not shown).

\subsection{Future Activity and Educational Attainment}

Pearson's correlations revealed a low positive significant correlation $(\mathrm{r}=0.39 ; p \leq 0.05)$ between participants' educational attainment and their FA score. Greater educational attainment correlated with an increased number of planned FAs.

\subsection{Future Activity among Age and Gender Subgroups: Construct Validity}

A two way MANOVA compared the mean FA scores in the four ACS domains between the age and gender groups. Significant differences were found between age groups $\left(\mathrm{F}(4,53)=3.39 ; p=0.02, \eta^{2}=0.20\right)$ and gender groups $\left(\mathrm{F}(4,53)=4.21 ; p=0.001 ; \eta^{2}=0.24\right)$ (see Table 1), but no interaction effect was found between them. One-way ANOVA showed significant differences between the FA scores of the two age groups with respect to the following test domains: social-cultural, low physical leisure, and high physical leisure. A difference between the genders was found only for the high physical leisure domain (see Table 3).

Similar results were obtained when the educational attainment variable was kept constant. Differences were found between age groups but not between genders. No interaction effect was found between age and gender on the FA score.

\subsection{Test-Retest Reliability of the Modified ACS}

A MANOVA repeated measures test showed no significant difference between the tests (see Table 4).

The Pearson correlation test values obtained between the test and retest scores (Table 5) indicate that the testretest reliability for most of variables is moderate-high. Hence, the number of activities planned for the future was similar in both test administrations.

\section{DISCUSSION}

The current study tested an expanded version of the ACS assessment that allows occupational therapists to obtain information on an individual's future activity plans in addition to examining past and present participation in leisure activities. The main question of the current study was, do older adults tend to continue former or current daily and leisure activities in the future or do they engage in new ones.

\subsection{Continuity in Old Age}

The results of the current study support the idea that older adults seek continuity between past and current activities when planning their future $[10,12,13]$. The continuity motive indicates that older adults desire stability with respect to behavior and activity patterns throughout their lives. They achieve continuity by maintaining existing or previous activity patterns into old age. This implies that a person who was active in his younger years will seek opportunities to stay active in the future [13]. The same tendency is manifested in this study, which indicates that the more active people are or were in the past, the more future activities they plan to participate in. The stability of leisure behavior throughout the lifespan can be viewed as a strategy assisting people to cope with the changes associated with ageing [19] and provides the ageing person with a way of maintaining internal continuity through external continuity [11]. The high correlations between the past, present, and future activity scores for the overall test, as well as for each domain, also indicate that patterns of activity remain stable throughout life and so lend further support to the continuity motive. People tend to maintain those activities they have engaged in present or past and not to plan new ones.

\subsection{Innovation in Old Age}

Innovation appeared to a similar extent in both age and gender groups. Some of the participants wished to engage in new activity experiences in the future (such as volunteering activities or activities with grandchildren). It can be assumed that the choice of activity reflects 
Table 3. Age and gender group means \pm SD and F values of ACS future activity scores.

\begin{tabular}{ccccccc}
\hline & \multicolumn{2}{c}{ Age group } & \multicolumn{2}{c}{ Gender } & \multicolumn{2}{c}{$\mathrm{F}\left(\eta^{2}\right)($ Observed power $)$} \\
\cline { 2 - 7 } & $\begin{array}{c}\text { Older adult } \\
\text { Group }(\mathrm{n}=33)\end{array}$ & $\begin{array}{c}\text { Elderly adult } \\
\text { group }(\mathrm{n}=27)\end{array}$ & $\begin{array}{c}\text { Female } \\
(\mathrm{n}=32)\end{array}$ & $\begin{array}{c}\text { Male } \\
(\mathrm{n}=28)\end{array}$ & Age & Gender \\
\hline Total score & $55.18 \pm 8.27$ & $45.26 \pm 14.01$ & $50.63 \pm 12.67$ & $50.28 \pm 11.83$ & $12.01^{*}(0.18)(0.93)$ & 0.65 \\
IADL score & $14.76 \pm 3.78$ & $13.15 \pm 4.01$ & $13.78 \pm 4.29$ & $14.32 \pm 3.53$ & 2.78 & 0.76 \\
Social-cultural & $16.21 \pm 2.92$ & $13.96 \pm 4.12$ & $15.41 \pm 3.83$ & $14.96 \pm 3.51$ & $5.65^{*}(0.09)(0.65)$ & 0.002 \\
Low physical leisure & $14.15 \pm 3.76$ & $11.37 \pm 4.92$ & $13.34 \pm 5.13$ & $12.39 \pm 3.69$ & $5.42^{*}(0.09)(0.63)$ & 0.11 \\
High physical leisure & $9.24 \pm 3.37$ & $6.59 \pm 3.62$ & $7.19 \pm 3.60$ & $9.04 \pm 3.63$ & $11.82^{* *}(0.17)(0.62)$ & $7.66^{* *}(0.12)(0.78)$ \\
\hline
\end{tabular}
${ }^{*} p<0.05 ;{ }^{* *} p<0.01$.

Table 4. Repeated measure MANOVA scores-test and retest means \pm SD and $\mathrm{F}$ values for past, current, and future activities.

\begin{tabular}{cccc}
\hline Variable $^{\mathrm{a}}$ & Test & Re-test & F \\
\hline IADL past & $17.00( \pm 1.61)$ & $16.82( \pm 2.60)$ & 0.08 \\
SocCult past & $18.09( \pm 3.11)$ & $17.27( \pm 2.45)$ & 0.82 \\
PhysLow past & $16.64( \pm 5.33)$ & $16.55( \pm 4.32)$ & 0.02 \\
PhysHigh past & $11.36( \pm 2.87)$ & $10.91( \pm 3.33)$ & 0.23 \\
IADL present & $14.86( \pm 1.80)$ & $14.68( \pm 2.83)$ & 0.12 \\
SocCult present & $13.55( \pm 2.45)$ & $12.86( \pm 2.60)$ & 10.23 \\
PhysLow present & $12.00( \pm 3.58)$ & $12.14( \pm 3.91)$ & 0.03 \\
PhysHigh present & $6.77( \pm 2.41)$ & $15.55( \pm 2.73)$ & 0.06 \\
IADL future & $15.36( \pm 1.80)$ & $15.91( \pm 3.05)$ & 0.12 \\
SocCult future & $15.91( \pm 2.84)$ & $15.09( \pm 5.38)$ & 0.00 \\
PhysLow future & $13.18( \pm 4.00)$ & $8.64( \pm 3.11)$ & 40.22 \\
PhysHigh future & $7.91( \pm 2.70)$ & & 0.62 \\
\hline
\end{tabular}

${ }^{a}$ The four domains of the Activity Card Sort (ACS) served as the study variables: IADL, instrumental activities of daily living; SocCult, social-cultural activities; PhysLow, low-physical leisure activities; PhysHigh, high-physical leisure activities.

Table 5. Pearson correlations tests between test and retest scores of the ACS total score and sub test scores in past, present and future.

\begin{tabular}{|c|c|c|c|c|}
\hline Variable & Pre-Test & Post-Test & $\mathrm{r}(p)$ & $p$ \\
\hline Total Past & $64.7( \pm 8.35)$ & $63.8( \pm 9.06)$ & 0.81 & $0.000^{* * *}$ \\
\hline IADL Past & $17.65( \pm 1.76)$ & $17.45( \pm 2.61)$ & 0.64 & $0.003^{* *}$ \\
\hline HevTar Past & $18.35( \pm 2.5)$ & $17.85( \pm 2.21)$ & 0.41 & $0.072(\mathrm{~ns})$ \\
\hline PhysLow Past & $17.3( \pm 4.55)$ & $16.95( \pm 3.79)$ & 0.88 & $0.000^{* * *}$ \\
\hline PhysHigh Past & $11.45( \pm 2.76)$ & $11.25( \pm 3.27)$ & 0.66 & $0.001^{* *}$ \\
\hline Total Present & $47.83( \pm 7.4)$ & $46.8( \pm 7.27)$ & 0.72 & $0.000^{* * *}$ \\
\hline IADL Present & $15.5( \pm 1.93)$ & $14.98( \pm 2.28)$ & 0.79 & $0.000^{* * *}$ \\
\hline HevTar Present & $14.1( \pm 2.04)$ & $13.48( \pm 2.2)$ & 0.66 & $0.002^{* *}$ \\
\hline PhysLow Present & $12.3( \pm 3.14)$ & $11.93( \pm 3.06)$ & 0.72 & $0.000^{* * *}$ \\
\hline PhysHigh Present & $6.75( \pm 2.58)$ & $6.43( \pm 2.32)$ & 0.49 & $0.028^{*}$ \\
\hline Total Future & $52.4( \pm 9.82)$ & $53.7( \pm 11.01)$ & 0.79 & $0.000^{*}$ \\
\hline IADL Future & $15.36( \pm 2.01)$ & $15.2( \pm 3.05)$ & 0.56 & $0.011^{*}$ \\
\hline HevTar Future & $15.5( \pm 2.78)$ & $15.95( \pm 2.95)$ & 0.84 & $0.000^{* * *}$ \\
\hline PhysLow Future & $13.2( \pm 3.46)$ & $3.8( \pm 4.43)$ & 0.75 & $0.000^{* * *}$ \\
\hline PhysHigh Future & $8.1( \pm 3.49)$ & $8.75( \pm 4.02)$ & 0.75 & $0.000^{* * *}$ \\
\hline
\end{tabular}


changed life circumstances. For example, a retired person might seek ways of filling free time with a new activity, and a person who had experienced the birth of a first grandchild might choose to spend time with the newborn.

The number of new FAs was rather low compared to the number of continuing FAs, indicating that the main tendency is to continue previous activities. We further observe that innovation is related to continuity, in that even some of the new activities chosen were an expansion of previous activities. For example, a participant who had engaged in certain craft activities in the past planned different craft activities for the future.

Previous studies showed that the phenomenon of innovation in old age is yet to be explored. The question whether innovation in old age is common or not is not definite, with some evidence showing it is not common [20-22], and some showing it is [23].

This study's findings of low levels of innovation in both gender and age groups are consistent with those of Iso-Ahola and colleagues [20], Levinson [21] and Parker [22] and support the expected construct validity. Nimrod [23] found that women exhibit more innovation than men, whereas this study found no significant difference between the two genders.

\subsection{Test-Retest Validity}

Results remained stable when participants were retested several weeks later. Thus, the new version of the ACS has moderate-strong test-retest validity and we anticipate stable results across repeated testing.

Significant differences were found between the two age groups in three activity domains (low physical, high physical and social-cultural leisure), with the older age group (elderly adults) participating less than the younger age group (older adults). These results support previous findings that there is a correlation between age and leisure participation [47]. In the IADL domain there was no difference between the age groups. A possible explanation might be that IADL are complex daily activities (such as preparing meals or doing household chores). These activities are vital to daily functioning at all ages [36]; hence healthy older people plan to maintain doing them throughout their ageing [48].

There were significant differences between men and women only in the high physical leisure domain. It seems that men and women have different needs and experiences of leisure, which lead them to choose different leisure activities. Previous studies have found that women prefer home-based social activities and spending time with family, while men prefer active social activities involving less direct communication with others and highly physically demanding leisure activities $[44,49,50]$. The findings of the current study support the claim that men prefer more highly physical leisure activities than women.

\section{LIMITATION}

The study was based on a convenience sample, and is therefore unrepresentative of the general population. It is recommended to conduct additional research on a larger, more representative sample.

Participants were not presented with a definition of "future" prior to their undertaking the "future planning" sorting task. As a result, the future could be understood as extending indefinitely from the next moment. We suggest providing participants with a definition of "future" in subsequent research using this tool.

\section{CONCLUSIONS}

In order to intervene with older clients, occupational therapists and other health professionals need to study the tendencies of this population regarding the continuity or innovation of future planned activities. The current research aimed to develop such a tool by expanding the ACS: an existing tool known to be suitable and valid for use with this population and which already enjoys widespread popularity. We found our expanded ACS to have significant moderate-high known group validity and test-retest reliability.

Use of the expanded test will enable practitioners to gain knowledge regarding the future activities planned by clients, and assist in establishing treatment goals in a client-centered intervention. This study supports existing knowledge of the process of future planning and adds to the scant literature regarding the older population and their future planning of IADL and leisure activities.

The new version of the ACS was found to be suitable in evaluating the past, present, and future activity profile of participants and, following additional testing, is expected to become a robust tool for conducting precise and reliable evaluations of the elderly population.

\section{REFERENCES}

[1] Bonder, B.R. and Wagner, M.B., Eds. (2001) Functional performance in older adults. 2nd Edition, F.A. Davis Company, Philadelphia.

[2] Leitner, M.J. and Leitner, S.F. (2004) Leisure in later life. Haworth Press, New York.

[3] Menec, V.H. (2003) The relation between everyday activities and successful aging: A 6-year longitudinal study. Journal of Gerontology: Social Sciences, 50B, S74-S82. doi:10.1093/geronb/58.2.S74

[4] Andrews, G., Clark, M. and Luszcz, M. (2002) Successful ageing in the Australian longitudinal study of ageing: Applying the MacArthur model cross-nationally. Journal of Social Issue, 58, 749-765. 
[5] Doney, R.M. and Packer, T.L. (2008) Measuring changes in activity participation of older Australians: Validation of the activity card sort-Australia. Australian Journal on Ageing, 27, 33-37. doi:10.1111/j.1741-6612.2007.00265.x

[6] World Health Organization (2001) International classification of functioning, disability and health (ICF). WHO, Geneva,

[7] Lefrancois, R., Leclerc, G. and Poulin, N. (1998) Predictors of activity involvement among older adults. Journal of Ageing Studies, 14, 135-152

[8] Clarke, A. and Warren, L. (2007) Hopes, fears and expectations about the future: What do older people's stories tell us about active ageing? Ageing and Society, 27, 465488. doi:10.1017/S0144686X06005824

[9] Lo, R. and Brown, R. (1999) Stress and adaptation: Preparation for successful retirement. Australian New Zealand Journal of Mental Health Nursing, 8, 30-38. doi:10.1046/j.1440-0979.1999.00127.x

[10] Nimrod, G. and Kleiber, D. (2007) Reconsidering change and continuity in later life: Toward an innovation theory of successful ageing. International Journal of Ageing and Human Development, 65, 1-22. doi:10.2190/Q4G5-7176-51Q2-3754

[11] Rosenkoetter, M.M. and Garris, J.M. (2001) Retirement planning, use of time, and psychological adjustment. Issues in Mental Health Nursing, 22, 703-722. doi:10.1080/016128401750434491

[12] Agahi, N., Ahacic, K. and Parker, M.G. (2006) Continuity of leisure participation from middle age to old age. Journal of Gerontology: B. Social Sciences, 61, 340-346.

[13] Atchley, R.C. (1993) Continuity theory and the evolution of activity in later adulthood. In: J. R. Kelly, Ed., Activity and Ageing: Staying Involved in Later Life, Sage, Newbury Park, 5-16.

[14] Haworth, J. and Lewis, S. (2005) Work, leisure and wellbeing. British Journal of Guidance and Counseling, 33, 67-79. doi:10.1080/03069880412331335902

[15] Hutchinson, S.L. and Kleiber, D.A. (2005) Leisure, constraints, and negative life events: Paradox and possibilities. In: Jackson, E.L., Ed., Constraints to Leisure, State College, Venture, 137-150

[16] Son, J.C., Yarnal, C. and Kerstetter, D. (2010) Engendering social capital through a leisure club for middle-aged and older women: Implications for individual and community health and well-being. Leisure Studies, 29, 67-83. doi:10.1080/02614360903242578

[17] Weng, P. (2010) Square leisure culture and the construction of a harmonious, healthy and civilized lifestyle. Proceedings of 11 th World Leisure Congress, Chuncheon, 189190.

[18] Yau, M.K. and Packer, T.L. (2002) Health and well-being through T'ai-Chi: Perceptions of older adults in Hong Kong. Leisure Studies, 21, 163-178. doi:10.1080/026143602110138850

[19] Elder, H. and Rudolph, P. (1999) Does retirement planning affect the level of retirement satisfaction? Financial Services Review, 8, 117-127. doi:10.1016/S1057-0810(99)00036-0
[20] Iso-Ahola, S.E., Jackson, E. and Dunn, E. (1994) Starting, ceasing and replacing leisure activities over the life span. Journal of leisure Research, 26, 227.

[21] Levinson, S. (1986) Leisure choices in retirement: Spillover or compensatory of preretirement activities? Master's Thesis, Bar-Ilan University, Ramat Gan.

[22] Parker, S. (1982) Work and retirement. George Allen and Unwin, London.

[23] Nimrod, G. (2008) In support of innovation theory: Innovation in activity patterns and life satisfaction among recently retired individuals. Ageing and Society, 28, 831846. doi:10.1017/S0144686X0800706X

[24] Hardcastle, S. and Taylor, A. (2005) Making space for a new exercise identity in an older body: A longitudinal qualitative study of a primary care intervention. Psychology of Sport and Exercise, 6, 173-188. doi:10.1016/j.psychsport.2003.12.002

[25] Nimrod, G. and Hutchinson, S. (2010) Innovation among older adults with chronic health conditions. Journal of Leisure Research, 41, 1-23.

[26] Stalp, M.C. (2006) Negotiating time and space for serious leisure: Quilting in the modern US home. Journal of Leisure Research, 38, 104-132.

[27] Nimrod, G. (2007) Expanding, reducing, concentrating, and diffusing: Post-retirement leisure behavior and life satisfaction. Leisure Sciences, 29, 91-111. doi:10.1080/01490400600983446

[28] Sachs, D., Schreuer, N., Dellavega, M., Yalon-Chamovitz, S. and "MATAM" Group. (2007) The Israeli adaptation of the occupational therapy practice framework: Theory to practice case studies. ISOT, Tel-Aviv.

[29] Bond, M.J., Clark, M.S., Smith, D.S. and Harris, R.D. (1995) Lifestyle activities of the elderly: Composition and determinants. Disability \& Rehabilitation, 17, 63-69. doi:10.3109/09638289509166629

[30] Malinowsky, C., Nygård, L. and Kottorp, A., (2011) Psychometric evaluation of a new assessment of the ability to manage technology in everyday life. Scandinavian Journal of Occupational Therapy, 18, 26-35. doi:10.3109/11038120903420606

[31] Bona, L.D. (2000) What are the benefits of leisure? An exploration using the leisure satisfaction scale. British Journal of Occupational Therapy, 63, 50-58.

[32] Brayman, S.J., Kirby, T.F., Misenheimer, A.M. and Short, M.M. (1976) Comprehensive occupational therapy evaluation scale. American Journal of Occupational Therapy, 30, 94-100.

[33] Law, M., Baptiste, S., McColl, S., Opzoomer, A., Pollock, N. and Polatajko, H. (1990) The Canadian occupational performance measure: An outcome measurement protocol for occupational therapy. Canadian Journal of Occupational Therapy, 57, 82-87.

[34] Matsutsuyu, J. (1969) The interest checklist. American Journal of Occupational Therapy, 23, 323-328.

[35] Smith, N.R., Kielhofner, G.Y. and Hawkins, J. (1986) The relationships between volition, activity pattern and life satisfaction in the elderly. The American Journal of Occupational Therapy, 40, 278-283. 


\section{doi:10.5014/ajot.40.4.278}

[36] Lawton, M.P. and Brody, E.M. (1969) Assessment of older people: Self-maintaining and instrumental activities of daily living. Gerontologist, 9, 179-186. doi:10.1093/geront/9.3_Part_1.179

[37] Baum, C.M. (1995) The contribution of occupation to function in persons with Alzheimer's disease. Journal of Occupation Science: Australia, 2, 59-67. doi:10.1080/14427591.1995.9686396

[38] Baum, C.M. and Edwards, D. (2001) Activity Card Sort (ACS). Test manual. Washington University School of Medicine, St. Louis.

[39] Baum, C.M., Perlmutter, M. and Edwards, D. (2000) Measuring function in Alzheimer's disease. Alzheimer's Care Quarterly, 1, 44-61.

[40] Hartman-Maeir, A., Soroker, N., Ring, H., Avni, N. and Katz, N. (2007) Activities, participation and satisfaction one-year post stroke. Disability and Rehabilitation, 29, 559-566. doi:10.1080/09638280600924996

[41] Katz, N., Karpin, H., Lak, A., Furman, T. and HartmanMaeir, A. (2003) Participation in occupational performance: Reliability and validity of the activity card sort. OTJR: Occupation, Participation and Health, 23, 10-17.

[42] Packer, T., Boshoff, K. and De Jonge, D. (2008) Development of the activity card sort-Australia. Australian Journal of Occupational Therapy, 55, 199-206. doi:10.1111/j.1440-1630.2007.00686.x

[43] Sachs, D. and Josman, N. (2003) The activity card sort: A factor analysis. OTJR: Occupation, Participation and Health, 23, 165-174.

[44] Karpin, H., Hartman-Maeir, A. and Katz, N. (2001) Leisure and IADL activity characteristics of adult and elderly population in Israel, according to the activity card sort. The Israeli Journal of Occupational Therapy, 10, H3$\mathrm{H} 22$.

[45] Seccombe, K. and Ishii-Kuntz, M. (1991) Perceptions of problems associated with ageing: Comparisons among four older age cohorts. Gerontologist, 31, 527-533. doi:10.1093/geront/31.4.527

[46] Gonen, D., Bar-Yossef, H., Torni-Feldman, T., Zilberman-Cohen, A., Forman, T. and Karpin, H. (1997) Preliminary research: Examining the validity of the Activity Card Sort and adapting it to Israel. Master's Thesis, Hebrew University, Hebrew.

[47] Kelly, J. and Freysinger, V. (2000) 21st century leisure: Current issues. Allyn \& Bacon, Boston.

[48] Fricke, J. and Unsworth, C. (2001) Time use and importance of instrumental activities of daily living. Australian Occupational Therapy Journal, 4, 118-131. doi:10.1046/j.0045-0766.2001.00246.x

[49] Shul-Bacon, M. (1997) The structure of the world of leisure of the elderly living in the community. Surveys and Reviews in Gerontology, 103, 20-21.

[50] Weinblatt, N. (2000) Prologue: Leisure in old age. Gerontology: Journal of Ageing Studies, 30, 9-12. 